\title{
Analysis of the incidence of tumor lysis syndrome in patients with hematological malignancies treated with rasburicase
}

\author{
EISEKI USAMI ${ }^{1}$, MICHIO KIMURA $^{1}$, MINA IWAI $^{1}$, HITOMI TERAMACHI $^{2}$ and TOMOAKI YOSHIMURA ${ }^{1}$ \\ ${ }^{1}$ Department of Pharmacy, Ogaki Municipal Hospital, Ogaki, Gifu 503-8502; \\ ${ }^{2}$ Laboratory of Clinical Pharmacy, Gifu Pharmaceutical University, Gifu 501-1196, Japan
}

Received December 16, 2016; Accepted March 16, 2017

DOI: $10.3892 /$ mco.2017.1232

\begin{abstract}
The purpose of this study was to assess the incidence of tumor lysis syndrome (TLS) in patients with hematological malignancies treated with rasburicase, and to evaluate the dose and duration of rasburicase administration. A total of 52 patients were enrolled. The background of the patients, incidence of TLS and laboratory data were retrospectively examined; in addition, the dose and duration of rasburicase administration and the factors affecting the onset of TLS were evaluated and compared among TLS risk categories. During the study period, $2(3.8 \%)$ of the patients developed clinical TLS and 24 (46.2\%) developed laboratory TLS (LTLS). Although the LTLS rate was very high, there were no life-threatening cases of TLS. The median daily dose of rasburicase administered to all patients was $7.5 \mathrm{mg} /$ day (interquartile range, 7.5-9.0 mg/day), and the daily weight-based dose was $0.147 \mathrm{mg} / \mathrm{kg} /$ day (range, $0.126-0.178 \mathrm{mg} / \mathrm{kg} /$ day). The administration duration was 3 days (interquartile range, 3-4 days). Additionally, there was no significant association between TLS risk classification and daily rasburicase administration dose, duration, or post-administration laboratory data. The factors affecting the onset of TLS included serum uric acid level, as well as serum creatinine and phosphate levels. Rasburicase was highly effective in the prevention and management of hyperuricemia, even at a low-dose (7.5 mg/day) and a duration that was 3 days shorter compared with that recommended by the manufacturer. Therefore, clinicians should administer rasburicase based on their clinical judgment, taking into consideration the cost-effectiveness of this therapy.
\end{abstract}

Correspondence to: Dr Eiseki Usami, Department of Pharmacy, Ogaki Municipal Hospital, 4-86 Minaminokawa-cho, Ogaki, Gifu 503-8502, Japan

E-mail: omhp2002@yahoo.co.jp

Key words: tumor lysis syndrome, rasburicase, hematological patients, cost simulation

\section{Introduction}

Tumor lysis syndrome (TLS) is considered to be an oncological emergency that may result in severe metabolic abnormalities, including hyperuricemia, hyperkalemia, hyperphosphatemia and hypocalcemia, in patients with rapidly proliferating and chemosensitive malignancies, such as high-grade lymphoma or acute lymphoblastic leukemia $(1,2)$. The prevention and management of TLS includes aggressive hydration and reduction or increase in the excretion of uric acid (UA) (3).

Allopurinol or febuxostat decrease the production of UA by inhibiting the enzyme xanthine oxidase and blocking the oxidation of xanthine. Therefore, following allopurinol or febuxostat administration, there is a time lag prior to the reduction in UA levels. By contrast, rasburicase, a recombinant urate oxidase, catalyzes the conversion of UA to allantoin, rapidly reducing UA levels (4). Although several studies have been conducted with the use of fixed, low-dose, or single-dose rasburicase (5-7), the manufacturer recommends a dose of $0.2 \mathrm{mg} / \mathrm{kg}$ daily to be administered for up to 7 days in Japan.

The objective of this retrospective review was to examine the incidence of TLS in patients with hematological malignancies treated with rasburicase and to evaluate the dose and duration of rasburicase administration.

\section{Patients and methods}

Patients. A total of 52 patients with hematological malignancies who received rasburicase at the Ogaki Municipal Hospital (Ogaki, Japan) between August, 2011 and July, 2016 were enrolled. The study protocol was reviewed and approved by the Ethics Committee at Ogaki Municipal Hospital (20161124-6).

Patient background. The backgrounds of patients who received rasburicase were investigated to determine their gender, age, weight, rasburicase administration, diagnosis, concomitant therapy for TLS, TLS risk category, spontaneous TLS, serum UA, potassium, phosphate, calcium and creatinine levels prior to and following rasburicase administration.

Incidence of TLS. The incidence of laboratory TLS (LTLS) and clinical TLS (CTLS) were examined. The TLS risk was classified based on the report by Calio et al (8). First, patients were required to have $\geq 2$ of the following abnormalities: 
Table I. Baseline characteristics of the study patients $(n=52)$.

\begin{tabular}{|c|c|}
\hline Study pop & $\begin{array}{l}\text { ulation, } \\
\qquad \mathrm{n}(\%)\end{array}$ \\
\hline \multicolumn{2}{|l|}{ Gender } \\
\hline Male & $27(51.9)$ \\
\hline Female & $25(48.1)$ \\
\hline \multicolumn{2}{|l|}{ Age, years } \\
\hline Median (interquartile range) & $68(58-76)$ \\
\hline \multicolumn{2}{|l|}{ Weight, kg } \\
\hline Median (interquartile range) & $57.6(49.2-63.2)$ \\
\hline \multicolumn{2}{|l|}{ Rasburicase administration } \\
\hline Daily dose, mg/day & $7.5(7.5-9.0)$ \\
\hline Daily weight-based dose, $\mathrm{mg} / \mathrm{kg} /$ day & $0.147(0.126-0.178)$ \\
\hline Duration, days & $3(3-4)$ \\
\hline Total dose, $\mathrm{mg}$ & $22.5(22.5-30.0)$ \\
\hline Weight-based dose & $13(25.0)$ \\
\hline Single fixed dose (7.5 mg/day) & $33(63.5)$ \\
\hline \multicolumn{2}{|l|}{ Diagnosis } \\
\hline \multicolumn{2}{|l|}{ Leukemia } \\
\hline Acute lymphoblastic leukemia & $8(15.4)$ \\
\hline Acute myelogenous leukemia & $8(15.4)$ \\
\hline Chronic myelogenous leukemia & $1(1.9)$ \\
\hline \multicolumn{2}{|l|}{ Lymphoma } \\
\hline Diffuse large B-cell lymphoma & $18(34.6)$ \\
\hline Peripheral T-cell lymphoma & $3(5.8)$ \\
\hline Mantle cell lymphoma & $2(3.8)$ \\
\hline Follicular lymphoma & $2(3.8)$ \\
\hline Angioimmunoblastic T-cell lymphoma & $2(3.8)$ \\
\hline Anaplastic large-cell lymphoma & $2(3.8)$ \\
\hline Adult T-cell lymphoma & $1(1.9)$ \\
\hline Hodgkin's disease & $1(1.9)$ \\
\hline Other lymphomas & $4(7.7)$ \\
\hline \multicolumn{2}{|l|}{ Concomitant therapy for TLS } \\
\hline Allopurinol or febuxostat & $26(50.0)$ \\
\hline Hydration & $52(100.0)$ \\
\hline \multicolumn{2}{|l|}{ TLS risk category } \\
\hline High-risk disease & $19(36.5)$ \\
\hline Intermediate-risk disease & $23(44.2)$ \\
\hline Low-risk disease & $10(19.2)$ \\
\hline \multicolumn{2}{|l|}{ Spontaneous TLS ${ }^{\mathrm{a}}$} \\
\hline Laboratory TLS & $5(9.6)$ \\
\hline
\end{tabular}

apresence of tumor lysis syndrome prior to chemotherapy initiation. Data are presented as number (\%) or median (interquartile range). TLS, tumor lysis syndrome.

Increased UA, increased potassium, increased phosphate, or decreased calcium, in order to be defined as having LTLS within 3 days prior to or up to 7 days after the initiation of chemotherapy. CTLS was diagnosed in patients with abnormalities such as increased serum creatinine level, seizures and cardiac dysrhythmia or death while experiencing LTLS.
Table II. Incidence of tumor lysis syndrome.

\begin{tabular}{lr}
\hline Findings & $\mathrm{N}(\%)$ \\
\hline Laboratory TLS & $24(46.2)$ \\
Hyperuricemia & $30(57.7)$ \\
Hyperkalemia & $6(11.5)$ \\
Hyperphosphatemia & $17(32.7)$ \\
Hypocalcemia & $18(34.6)$ \\
Clinical TLS & $2(3.8)$ \\
Increased creatinine level & $2(3.8)$ \\
Seizures & $0(0.0)$ \\
Cardiac dysrhythmia & $0(0.0)$ \\
Death & $0(0.0)$ \\
\hline
\end{tabular}

TLS, tumor lysis syndrome.

Comparison among TLS risk categories. Hematological malignancies were classified into high-risk disease (HRD), intermediate-risk disease (IRD) and low-risk disease (LRD) groups based on their TLS risk. The rasburicase daily dose, duration and total dose were evaluated and compared among different groups. In addition, serum UA, potassium, phosphate, calcium and creatinine levels were evaluated at baseline, at $24 \mathrm{~h}$ and 7 days after rasburicase administration.

Comparison of incidence of LTLS. The same comparison was performed between the LTLS and non-LTLS groups.

Cost simulation. The difference in the total cost of rasburicase at the dose administered in the present study and at the weight-based dose approved in Japan was assessed. A simulation of the estimated cost if all patients were administered rasburicase for 5 days was also created. The costs were calculated using Japanese medicine prices as of November, 2016.

Statistical analysis. The data were analyzed using JMP software, version 5.0.1J (SAS Institute Japan Ltd., Tokyo, Japan). The Mann-Whitney U-test was used for the comparison of the patient backgrounds between the LTLS and the non-LTLS groups. The Kruskal-Wallis test was used for comparisons among each TLS risk categories. The recorded P-values were two-sided and $\mathrm{P}<0.05$ was considered to indicate a statistically significant difference.

\section{Results}

Patient background. The baseline characteristics of the 52 patients who received rasburicase are listed in Table I. The median daily dose of rasburicase administered to all patients was $7.5 \mathrm{mg}$ /day (interquartile range, 7.5-9.0 mg/day) and the daily weight-based dose was $0.147 \mathrm{mg} / \mathrm{kg} / \mathrm{day}$ (interquartile range, $0.126-0.178 \mathrm{mg} / \mathrm{kg} /$ day). The administration duration was 3 days (interquartile range, 3-4 days) and the total dose was $22.5 \mathrm{mg}$ (interquartile range, 22.5-30.0 mg). A total of 17 patients $(32.7 \%)$ had leukemia and $35(67.3 \%)$ had malignant lymphoma; 19 patients had HRD (36.5\%), 23 had IRD 
Table III. Comparison of the rasburicase treatment doses and laboratory data among tumor lysis syndrome risk categories.

\begin{tabular}{|c|c|c|c|c|}
\hline & HRD & IRD & LRD & P-value \\
\hline \multicolumn{5}{|l|}{ Rasburicase administration } \\
\hline Daily dose, mg/day & $7.5(7.5-9.0)$ & $7.5(7.5-7.5)$ & $7.5(7.5-7.5)$ & 0.928 \\
\hline Daily weight-based dose, $\mathrm{mg} / \mathrm{kg} /$ day & $0.152(0.147-0.181)$ & $0.140(0.124-0.174)$ & $0.132(0.116-0.181)$ & 0.495 \\
\hline Duration, days & $3(3-4)$ & $3(3-4)$ & $4(3-4)$ & 0.382 \\
\hline Total dose, $\mathrm{mg}$ & $27.0(22.5-33)$ & $22.5(22.5-34.5)$ & $22.5(22.5-30.0)$ & 0.392 \\
\hline \multicolumn{5}{|l|}{ Serum UA, mg/dl } \\
\hline Baseline & $5.5(4.0-10.7)$ & $5.6(2.9-7.9)$ & $4.5(3.8-6.0)$ & 0.516 \\
\hline $24 \mathrm{~h}$ after rasburicase administration & $0.1(0.1-0.1)$ & $0.1(0.1-0.2)$ & $0.1(0.1-0.1)$ & 0.271 \\
\hline 7 days after rasburicase administration & $2.1(1.6-3.0)$ & $2.1(1.3-3.0)$ & $1.9(1.3-3.6)$ & 0.895 \\
\hline \multicolumn{5}{|l|}{ Serum potassium, mEq/1 } \\
\hline Baseline & $4.0(3.6-4.1)$ & $4.2(3.7-4.5)$ & $4.1(4.0-4.2)$ & 0.438 \\
\hline $24 \mathrm{~h}$ after rasburicase administration & $3.9(3.7-4.2)$ & $4.2(3.8-4.4)$ & $4.1(3.9-4.3)$ & 0.540 \\
\hline 7 days after rasburicase administration & $4.2(3.6-4.4)$ & $3.9(3.6-4.6)$ & $4.2(4.1-4.3)$ & 0.810 \\
\hline \multicolumn{5}{|l|}{ Serum phosphate, mg/dl } \\
\hline Baseline & $3.0(3.0-3.5)$ & $3.6(3.0-3.9)$ & $3.0(3.0-3.5)$ & 0.263 \\
\hline $24 \mathrm{hl}$ after rasburicase administration & $3.6(3.0-4.4)$ & $3.7(2.9-4.6)$ & $3.0(2.8-3.3)$ & 0.161 \\
\hline 7 days after rasburicase administration & $3.0(2.7-4.3)$ & $3.6(3.0-4.2)$ & $3.0(2.8-3.3)$ & 0.277 \\
\hline \multicolumn{5}{|l|}{ Serum calcium, mg/dl } \\
\hline Baseline & $8.7(8.5-8.9)$ & $8.5(8.3-8.9)$ & $8.6(8.4-8.9)$ & 0.962 \\
\hline $24 \mathrm{~h}$ after rasburicase administration & $8.5(8.0-8.9)$ & $8.3(7.6-8.6)$ & $8.4(8.3-8.7)$ & 0.493 \\
\hline 7 days after rasburicase administration & $8.4(7.7-8.8)$ & $8.4(7.8-8.6)$ & $8.6(8.2-8.7)$ & 0.466 \\
\hline \multicolumn{5}{|l|}{ Serum creatinine, $\mathrm{mg} / \mathrm{dl}$} \\
\hline Baseline & $0.61(0.56-1.06)$ & $0.68(0.57-0.93)$ & $0.63(0.52-0.83)$ & 0.541 \\
\hline $24 \mathrm{~h}$ after rasburicase administration & $0.58(0.52-1.03)$ & $0.59(0.46-0.92)$ & $0.58(0.43-0.75)$ & 0.367 \\
\hline 7 days after rasburicase administration & $0.57(0.47-0.77)$ & $0.51(0.47-0.61)$ & $0.54(0.51-0.70)$ & 0.971 \\
\hline
\end{tabular}

Data are presented as median (interquartile range). HRD, high-risk disease; IRD, intermediate-risk disease; LRD, low-risk disease; UA, uric acid.

(44.2\%) and 10 had LRD (19.2\%) in the TLS risk categories; 5 patients $(9.6 \%)$ had spontaneous TLS (presence of TLS prior to chemotherapy initiation).

Incidence of TLS. The incidences of TLS are listed in Table II. Overall, 24 patients (46.2\%) developed LTLS. Among these, $30(57.7 \%)$ had hyperuricemia, $6(11.5 \%)$ had hyperkalemia, 17 (32.7\%) had hyperphosphatemia and 18 (34.6\%) had hypocalcemia. Additionally, 2 of the patients (3.8\%) developed CTLS (only increased serum creatinine level).

Comparison among TLS risk categories. A comparison of the rasburicase doses and laboratory data in the HRD, IRD and LRD groups is shown in Table III. There was no significant difference among the groups.

Comparison between LTLS and non-LTLS groups. A comparison between the LTLS and the non-LTLS groups is shown in Table IV. The baseline data for serum UA and creatinine levels in the LTLS group were significantly higher compared with those of the non-LTLS group. Additionally, the data obtained $24 \mathrm{~h}$ after rasburicase administration for serum phosphate and creatinine levels in the LTLS group were significantly higher compared with those in the non-LTLS group. There was no significant difference in serum potassium at any point (baseline, $24 \mathrm{~h}$, or 7 days after rasburicase administration).

\section{Discussion}

TLS consists of serious, potentially fatal complications in patients with hematological malignancies undergoing anticancer chemotherapy. Allopurinol has been used for several years for the prevention of TLS-related hyperuricemia. Recently, rasburicase was found to confer a potential advantage over allopurinol with its rapid onset of action, reducing the pre-existing pool of UA within a few $h(9)$.

In the present study, patients with HRD as well as those with IRD received rasburicase. Although the baseline serum UA level of 29 patients (55.8\%) exceeded the normal range, it declined to undetectable levels within $24 \mathrm{~h}$ after rasburicase administration. Only 1 patient who received a single dose of rasburicase had an increased serum UA level above the normal range at 7 days. The incidence of LTLS was very high (46.2\%); however, no patients developed renal events requiring dialysis 
Table IV. Comparison of rasburicase treatment doses and laboratory data between laboratory and non-laboratory TLS groups.

\begin{tabular}{|c|c|c|c|}
\hline & Laboratory TLS $(n=24)$ & Non-laboratory TLS (n=28) & P-value \\
\hline \multicolumn{4}{|l|}{ Rasburicase administration } \\
\hline Daily dose, mg/day & $7.5(7.5-9.0)$ & $7.5(7.5-9.0)$ & 0.410 \\
\hline Daily weight-based dose, $\mathrm{mg} / \mathrm{kg} / \mathrm{day}$ & $0.144(0.121-0.176)$ & $0.151(0.128-0.182)$ & 0.440 \\
\hline Duration, days & $3(3-3)$ & $3(3-4)$ & 0.987 \\
\hline Total dose, mg & $22.5(22.5-31.5)$ & $22.5(22.5-30.0)$ & 0.528 \\
\hline TLS risk category & & & 0.022 \\
\hline HRD & $11(45.8)$ & $8.0(28.6)$ & \\
\hline IRD & $12(50.0)$ & $11.0(39.3)$ & \\
\hline LRD & $1(4.2)$ & $9.0(32.1)$ & \\
\hline \multicolumn{4}{|l|}{ Serum UA, mg/dl } \\
\hline Baseline & $9.1(5.9-12.7)$ & $3.8(2.6-4.7)$ & $<0.001$ \\
\hline $24 \mathrm{~h}$ after rasburicase administration & $0.2(0.1-0.2)$ & $0.1(0.1-0.1)$ & 0.698 \\
\hline 7 days after rasburicase administration & $2.8(1.9-3.9)$ & $1.8(1.0-2.3)$ & 0.008 \\
\hline \multicolumn{4}{|l|}{ Serum potassium, mEq/1 } \\
\hline Baseline & $4.2(3.7-4.5)$ & $4.0(3.7-4.2)$ & 0.172 \\
\hline $24 \mathrm{~h}$ after rasburicase administration & $4.2(3.8-4.5)$ & $4.0(3.8-4.3)$ & 0.070 \\
\hline 7 days after rasburicase administration & $4.1(3.7-4.4)$ & $4.2(3.7-4.4)$ & 0.280 \\
\hline \multicolumn{4}{|l|}{ Serum phosphate $(\mathrm{mg} / \mathrm{dl})$} \\
\hline Baseline & $3.5(3.1-4.0)$ & $3.1(3.0-3.8)$ & 0.171 \\
\hline $24 \mathrm{~h}$ after rasburicase administration & $3.8(3.0-4.8)$ & $3.0(2.9-3.7)$ & 0.002 \\
\hline 7 days after rasburicase administration & $3.8(3.0-4.7)$ & $3.0(2.8-3.8)$ & 0.029 \\
\hline \multicolumn{4}{|l|}{ Serum calcium, mg/dl } \\
\hline Baseline & $8.8(8.3-9.2)$ & $8.5(8.3-8.9)$ & 0.023 \\
\hline $24 \mathrm{~h}$ after rasburicase administration & $8.3(7.7-8.8)$ & $8.4(8.3-8.7)$ & 0.753 \\
\hline 7 days after rasburicase administration & $8.2(7.7-8.8)$ & $8.6(8.1-8.8)$ & 0.183 \\
\hline \multicolumn{4}{|l|}{ Serum creatinine, $\mathrm{mg} / \mathrm{dl}$} \\
\hline Baseline & $0.88(0.68-1.34)$ & $0.57(0.47-0.68)$ & $<0.001$ \\
\hline $24 \mathrm{~h}$ after rasburicase administration & $0.84(0.59-1.31)$ & $0.49(0.44-0.62)$ & $<0.001$ \\
\hline 7 days after rasburicase administration & $0.64(0.51-0.83)$ & $0.51(0.44-0.58)$ & 0.059 \\
\hline
\end{tabular}

Data are presented as median (interquartile range) or number (\%). TLS, tumor lysis syndrome; HRD, high-risk disease; IRD, intermediate-risk disease; LRD, low-risk disease; UA, uric acid.

or emergence of clinical TLS. All the patients who experienced LTLS had spontaneous hyperuricemia that presented prior to chemotherapy initiation. Therefore, rasburicase administration is very important for such patients.

There was no significant difference in the daily dose, weight-based daily dose, administration duration, or total dose of rasburicase in terms of TLS risk classification and between the LTLS and non-LTLS groups. The approved rasburicase dose in Japan is $0.2 \mathrm{mg} / \mathrm{kg} /$ day for up to 7 days. However, several studies indicated that a shorter treatment duration or low-dose rasburicase was also effective. Vadhan-raj et al reported that single-dose rasburicase $(0.15 \mathrm{mg} / \mathrm{kg} / \mathrm{day})$ was effective for the prevention of hyperuricemia; however, $12.5 \%$ of high-risk patients required a second dose. McBride et al reported that a 6-mg dose of rasburicase may represent an optimal balance of cost-effectiveness and efficacy (6). Campara et al reported that a single low $(0.15 \mathrm{mg} / \mathrm{kg})$ dose of rasburicase based on optimal body weight was sufficient to lower urate levels and appeared as effective as the significantly higher doses for multiple days (10). Herrington et al had adjusted their hyperuricemia algorithm to determine the 3- or 6-mg low-dose rasburicase on the baseline UA level (11). Owing to the relatively high cost associated with its use, rasburicase is typically administered at low doses and for $<5$ days in patients with malignancies attributed to lead exposure to minimize the cost of treatment.

In the present study, the daily dose of rasburicase was $7.5 \mathrm{mg} /$ day (interquartile range, $7.5-9.0 \mathrm{mg} / \mathrm{day}$ ) and the daily weight-based dose was $0.147 \mathrm{mg} / \mathrm{kg} /$ day (interquartile range, $0.126-0.178 \mathrm{mg} / \mathrm{kg} / \mathrm{day}$ ), which was lower than the manufacturer's recommended rasburicase dose. Additionally, the duration of rasburicase administration was short. The median duration was 3 days (interquartile range, 3-4 days), ranging from 1 to 9 days. Only 3 patients (5.7\%) received single-dose rasburicase; they did not require a second dose, and no patient developed serious TLS. If rasburicase was administered at weight-based doses in all 52 patients in this study, the cost 
would increase by $\sim 1.5$-fold, from $¥ 10,817,291$ to $¥ 15,712,580$, and by $\sim 2.1$-fold, to $¥ 22,502,255$, if administered for 5 days. To the best of our knowledge, rasburicase is effective for the prevention of TLS in patients with hematological malignancies, even at a low dose and with short-term administration. Patients should be closely monitored, as rasburicase administration may be deemed necessary according to clinical judgment, based on the biological abnormalities.

In addition, serum creatinine and phosphate levels were significantly higher in the LTLS group after $24 \mathrm{~h}$ of rasburicase administration. Although the serum UA level decreased with rasburicase after chemotherapy, it is crucial to monitor serum creatinine and phosphate levels within $24 \mathrm{~h}$.

In summary, the results of our study indicate that there is no significant association between rasburicase daily dose, duration, or post-administration laboratory data and TLS risk classification. Factors that may indicate the onset of TLS and are important to monitor include serum UA, creatinine and phosphate levels. Rasburicase was highly effective for the prevention and management of hyperuricemia, even at a low-dose (7.5 mg/day) and with a short duration of administration (3 days), which is below the manufacturer's recommended dose. Clinicians should administer rasburicase based on their clinical judgment, taking into consideration the cost-effectiveness of this therapy.

\section{References}

1. Bessmertny O, Robitaille LM and Cairo MS: Rasburicase: A new approach for preventing and/or treating tumor lysis syndrome. Curr Pharm Des 11: 4177-4185, 2005.
2. Hochberg J and Cairo MS: Tumor lysis syndrome: Current perspective. Haematologica 93: 9-13, 2008

3. Coiffier B, Altman A, Pui CH, Younes A and Cairo MS Guidelines for the management of pediatric and adult tumor lysis syndrome: An evidence-based review. J Clin Oncol 26: 2767-2778, 2008.

4. Oldfield V and Perry CM: Rasburicase: A review of its use in the management of anticancer therapy-induced hyperuricaemia. Drugs 66: 529-545, 2006.

5. Feng X, Dong K, Pham D, Pence S, Inciardi J and Bhutada NS: Efficacy and cost of single-dose rasburicase in prevention and treatment of adult tumour lysis syndrome: A meta-analysis. J Clin Pharm Ther 38: 301-308, 2013.

6. McBride A, Lathon SC, Boehmer L, Augustin KM, Butler SK and Westervelt P: Comparative evaluation of single fixed dosing and weight-based dosing of rasburicase for tumor lysis syndrome. Pharmacotherapy 33: 295-303, 2013.

7. Reeves DJ and Bestul DJ: Evaluation of a single fixed dose of rasburicase $7.5 \mathrm{mg}$ for the treatment of hyperuricemia in adults with cancer. Pharmacotherapy 28: 685-690, 2008.

8. Cairo MS, Coiffier B, Reiter A and Younes A; TLS Expert Panel: Recommendations for the evaluation of risk and prophylaxis of tumour lysis syndrome (TLS) in adults and children with malignant diseases: An expert TLS panel consensus. Br J Haematol 149: 578-586, 2010.

9. Mughal TI, Ejaz AA, Foringer JR and Coiffier B: An integrated clinical approach for the identification, prevention, and treatment of tumor lysis syndrome. Cancer Treat Rev 36: 164-176, 2010.

10. Campara M, Shord SS and Haaf CM: Single-dose rasburicase for tumour lysis syndrome in adults: Weight-based approach. J Clin Pharm Ther 34: 207-113, 2009.

11. Herrington JD and Dinh BC2: Fixed, low-dose rasburicase for the treatment or prevention of hyperuricemia in adult oncology patients. J Oncol Pharm Pract 21: 111-117, 2015. 